\title{
A COMPLEX REVIEW OF THE POSSIBILITIES OF RESIDUAL STRESS ANALYSIS USING MOVING 2D AND 3D DIGITAL IMAGE CORRELATION SYSTEM
}

\author{
HAGARA Martin ${ }^{1}$, PÁSTOR Miroslav ${ }^{1 *}$ \\ ${ }^{I}$ Technical University of Košice, Faculty of Mechanical Engineering, Department of Applied Mechanics and \\ Mechanical Engineering, Letná 1/9, 04200 Košice-Sever, Slovakia, e - mail: miroslav.pastor@tuke.sk
}

\begin{abstract}
Understanding the levels of residual stresses in the material is very important in predicting the service life of structural elements. One of the most widely used techniques to quantify them is the drilling method, where a small hole is milled in the structure. If the residual stresses are present, stress redistribution will occur, resulting in deformation of the hole surroundings. Nowadays, there is an effort to replace the conventionally used strain gauges, i.e. special strain gauge rosettes, with full-field optical experimental techniques. This paper deals with analysing the possibilities of measuring the relieved strains/stresses with a unique drilling/measuring device, which, unlike other non-commercial measuring systems, uses the moving digital image correlation (DIC) system. Since correlation systems do not tend to move during operation, an analysis was performed describing the effect of changing the position of the single and stereo camera correlation systems on the quality of the results of the strain/stress analysis performed in the vicinity of the milled hole. The conclusion from the analyses performed is that there is no significant accumulation of correlation errors during measurement. Therefore, the information on the magnitudes of the strains/stresses relieved obtained by the moving DIC system can be used to quantify the residual stresses with an expected error corresponding to the sensitivity of this full-field optical experimental technique.
\end{abstract}

KEYWORDS: residual stress; hole drilling; drilling device; positioning; digital image correlation

\section{Introduction}

Residual stresses arise in the material due to various technological processes, sudden temperature changes or surface structure changes such as oxidation or corrosion. As these stresses are easily overlooked, they can superimpose with operational stresses, and their determination is an essential part of the experimental mechanic's work.

A commonly used semi-destructive method of quantifying residual stresses is the holedrilling method, where a blind or through-hole is milled into the structure being analyzed [14]. In the presence of residual stresses, the surroundings of the created hole are deformed, which is recorded by specialized strain gauge rosettes. Based on the methodology described in ASTM E837-13a [5], the levels of residual stresses in thin and thick specimens, respectively, are determined. Specific drilling systems are used to mill out the holes, and their design (see Fig. 1) is implemented so that these holes are created with high precision concentrically with the applied strain gauge rosette.

To speed up the measurement itself and be able to evaluate the deformations relieved at multiple locations, the combination of the hole-drilling method with non-contact full-field methods is now becoming more common. In particular, optical measuring systems based on electronic speckle-pattern interferometry (ESPI) or digital image correlation (DIC) are used. Since the principle of these systems is to record images of the parts to be analysed at each measurement step, their application with commercially produced drilling devices is complicated (or impossible). The main reason for this is the overlapping of the view of the 
analysed object by the design of the drilling device, which allows either capturing the object from a greater distance (leading to a reduction of the image resolution) or the design and implementation of custom portable drilling devices $[6,7]$.

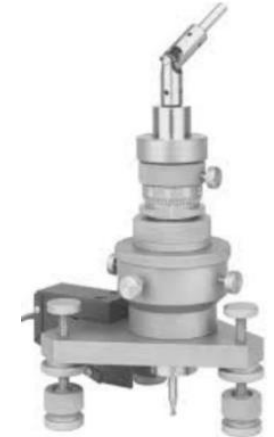

a)

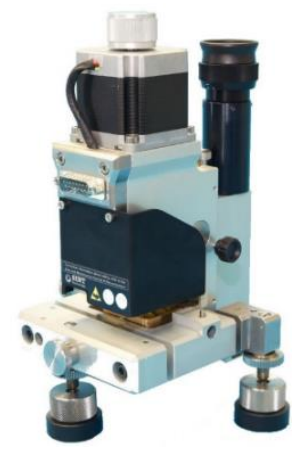

b)

Fig. 1 Commercially available drilling devices: a) Vishay RS-200, b) MTS SINT 3000

The authors have designed a unique drilling device allowing a single-camera (2D) or stereo-camera (3D) digital image correlation system Q-400 Dantec Dynamics, or a polariscope Vishay Micro-Measurements LF/Z-2 working on the principle of the PhotoStress method. Unlike drilling devices designed by other authors, this device is unique in that it allows horizontal and vertical movement of not only the milling cutter but also the correlation system (Fig. 2) and thus, the images can be acquired with the desired quality from a suitable distance for different specimen shapes and thicknesses [8].

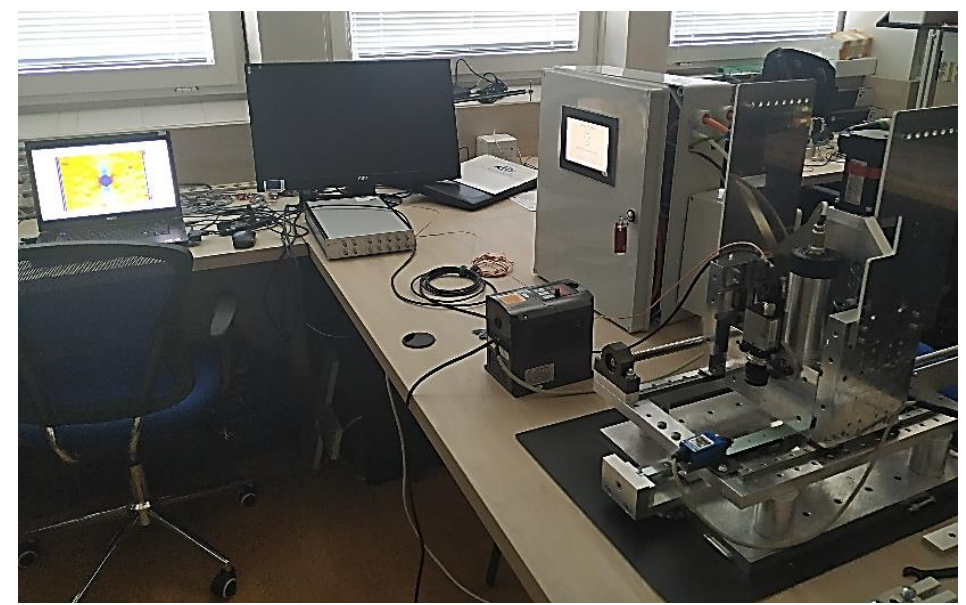

Fig. 2 Drilling/measuring device with automatic measuring mode designed by the authors

The proposed device was tested for structural rigidity, positioning accuracy and blind-hole formation [9]. This paper deals with a complex assessment of the measurement aspects and the possibility of using the DIC system Q-400 Dantec Dynamics for residual stress analysis in conjunction to change the mutual positions of the correlation and drilling system, which is not a common practice in terms of the DIC principle.

\section{Displacement and strain analysis using DIC}

Digital image correlation is a modern non-contact optical experimental technique, allowing to measure displacements and strains of the analyzed object captured by one or more cameras. If the measurement is performed using a single camera (Fig. 3a), only displacements or strains of a flat sample recorded in a plane parallel to the image plane of the camera can be analysed. However, to avoid correlation errors that could adversely affect the results of the analysis, it is necessary to ensure that the surface of the specimen to be analysed is parallel to the image 
plane of the camera throughout the measurement process. In the case of stereo-camera systems (Fig. 3b), this condition does not need to be met and the measurement results in information about all the displacement components in space, or strain fields, and the object to be analysed can be either a planar specimen or a specimen with a rounded spatial contour.
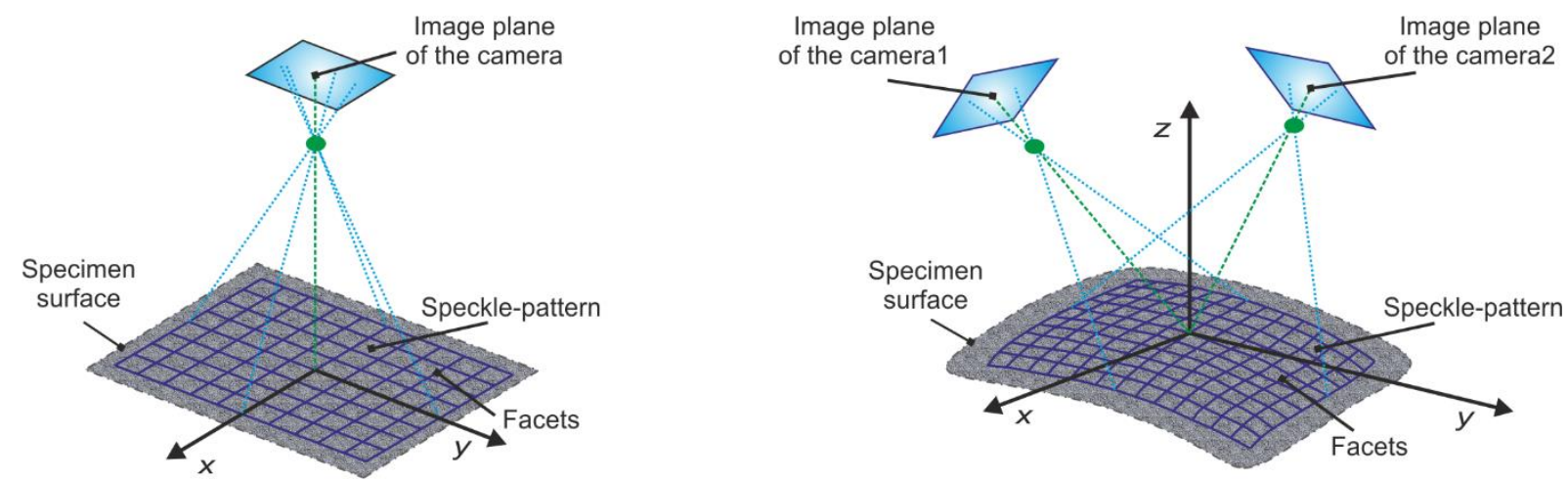

Fig. 3 Measurement principle using: a) 2D DIC, b) 3D DIC

\subsection{Digital image correlation system Q-400 Dantec Dynamics}

The authors of this paper performed all the described experiments using a low-speed digital image correlation system Q-400 Dantec Dynamics with the technical specification given in Table 1. This optical system typically comes with one or two cameras. Since the cameras do not have any internal memory, the transfer of images directly to the computer is done via an external FireWire800 CardBus card with a data transfer rate of $800 \mathrm{Mbit} / \mathrm{s}$. The synchronization of the cameras is provided by the TU-4XB bus. The data transfer to the laptop with the Istra4D control program, which is used to control and evaluate the measurement, is provided by a high-speed serial bus with the IEEE 1394 interface. The correlation system uses a white light reflector to ensure optimum illumination conditions.

Tab. 1 Technical specification of Q-400 Dantec Dynamics digital image correlation system

\begin{tabular}{|c|c|}
\hline Optics & $\begin{array}{l}\text { Schneider Kreuznach Germany lenses, CCD sensor with a maximum } \\
\text { image resolution of } 5 \mathrm{Mpx}(2452 \times 2056 \mathrm{px})\end{array}$ \\
\hline $\begin{array}{l}\text { Measurement } \\
\text { area }\end{array}$ & for standard lenses: several $\mathrm{mm}^{2}-$ several $\mathrm{m}^{2}$ \\
\hline Measuring range & displacements: $10^{-5}$ of the image field size, strains: $0.01-100 \%$ \\
\hline Aperture time & from $500 \mathrm{~ms}$ \\
\hline Results form & $\begin{array}{l}\text { the spatial contour of the object's surface } \\
\text { 2D or 3D displacements (depending on the number of cameras used) } \\
\text { strains at each point }\end{array}$ \\
\hline $\begin{array}{l}\text { Control } \\
\text { electronics }\end{array}$ & $\begin{array}{l}\text { laptop with Windows } 7 \text { operating system and Istra4D control software } \\
16 \text {-bit AD/DA converter ( } 8 \text { channels with voltage range from } \pm 0.05 \mathrm{~V} \text { to } \\
\pm 10 \mathrm{~V})\end{array}$ \\
\hline Illumination & halogen reflector with white light \\
\hline
\end{tabular}

\subsection{Basic principle of Dantec Dynamics digital image correlation systems}

The correlation algorithm of the Dantec Dynamics correlation systems is based on a pseudo-affine transformation that allows the acquisition of information about the so-called transform coordinates of the analysed object points. Let us denote with symbols $a_{0} \ldots a_{7}$ the transformation parameters of possible displacement, elongation, shear or twisting of the facet 
(Fig. 4). To determine the transformation coordinates $x^{*}$ and $y^{*}$ according to the pseudoaffine transformation the following applies

$$
\begin{aligned}
& x^{*}\left(a_{0}, a_{1}, a_{2}, a_{3}, x, y\right)=a_{0}+a_{1} x+a_{2} y+a_{3} x y, \\
& y^{*}\left(a_{4}, a_{5}, a_{6}, a_{7}, x, y\right)=a_{4}+a_{5} x+a_{6} y+a_{7} x y .
\end{aligned}
$$

The $a_{0} \ldots a_{7}$ parameters are unknown parameters which, after accounting for photogrammetric corrections, are determined by minimizing the difference between the grey level values of point (pixel) $g\left(x^{*}, y^{*}\right)$ in the deformed image and the corresponding grey level $f(x, y)$ in the reference image

$$
\min _{a_{0}, \ldots, a_{7}, i_{0}, i_{1}} \sum_{x, y}\left\|f(x, y)-\left(i_{0}+i_{1} \cdot g\left(x^{*}(x, y), y^{*}(x, y)\right)\right)\right\|,
$$

where $i_{0}$ and $i_{1}$ are the illumination parameters [10].
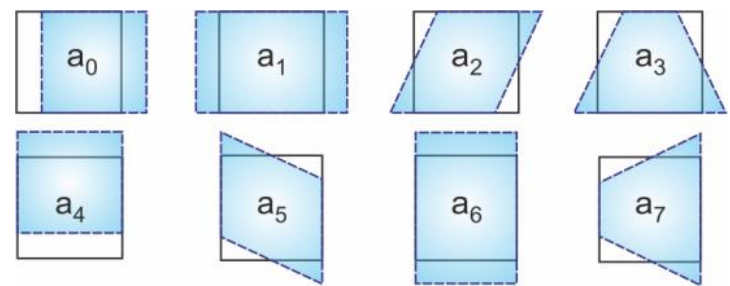

Fig. 4 Transformation parameters used in the Dantec Dynamics correlation algorithm based on pseudo-affine transformation

The intensities of individual points (pixels) are compared in small image elements called facets. If we determine the position of each point of an object in this way, we obtain the three-dimensional coordinates of its surface. The strains in the case of Dantec Dynamics correlation systems are determined from the analysis of the curvatures of the local facets used in the correlation process or the deformation gradients.

\subsection{Influence of smoothing on the results of strain/stress analysis performed in the vicinity of the hole using the Q-400 Dantec Dynamics correlation system}

When working with Dantec Dynamics correlation systems, it is essential to work correctly with data smoothing to obtain adequate results. There are several ways to smooth the data in the form of contour points or displacements. The first option is to smooth them directly by adjusting the correlation parameter, i.e. selecting a larger dimension of the touching facets. In this case, there is a loss of data resolution, which is not desirable in a strain/stress analysis performed around stress concentrators. This phenomenon can be prevented by overlapping the facets, i.e. by adjusting the virtual grid parameter, which is a constant indicating the distance between the centres of adjacent facets - the points at which the magnitudes of displacements and strains are evaluated, to the selected facet size. In addition, the Istra4D software offers to smooth fields with inhomogeneously distributed deformation the possibility of local regression, i.e. a filter that, according to [11] approximates the surface described by secondorder polynomials to third-order data. This type of smoothing is designed to preserve local extrema, allowing the user to specify the level of contour and displacement smoothing, depending on the chosen kernel size. If this filter is not activated, the strain field is obtained from analysing the local facets curvatures. On the other hand, increasing the smoothing level increases the influence of the deformation gradient on the calculation of the strains. In practice, when using this filter with kernel sizes larger than $7 \times 7$, the strains are already determined from the deformation gradient alone. 
The effect of smoothing on the stress analysis results can be seen in Fig. 5, which shows the analysis results on a specimen with a hole when subjected to the uniaxial tensile force applied in the y-axis direction and at variously selected smoothing levels [12]. While the results without smoothing are analysed (Fig. 5a), it is possible to observe very noisy data on the specimen surface with a significant range in the obtained values of the equivalent stresses. A significant change in the results occurs when the strains are calculated from the deformation gradient. By comparing the stress fields obtained for the low smoothing level of $7 \times 7$ (Fig. 5b), the medium smoothing level of $19 \times 19$ (Fig. 5c), and the highest smoothing level of $31 \times 31$ (Fig. $5 \mathrm{~d}$ ), respectively, it can be noted that the setting of the appropriate smoothing level plays an important role when performing experimental analyses using Dantec Dynamics correlation systems.
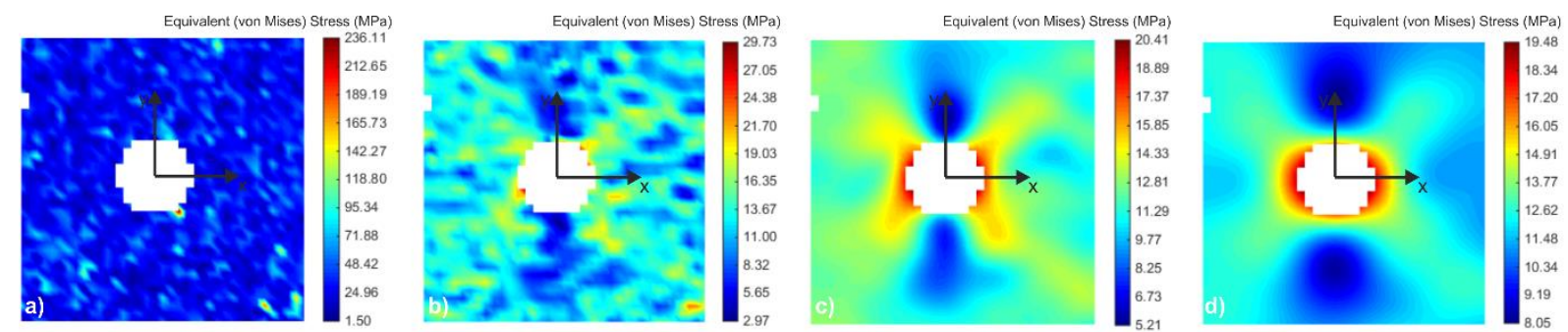

Fig. 5 Equivalent von Mises stress fields obtained at different kernel sizes: a) without smoothing, b) $7 \times 7$, c) $19 \times 19$, d) $31 \times 31$ [12]

By comparing the results obtained experimentally with those obtained numerically by the finite element method (FEM), the authors determined the optimal smoothing levels for the individual facet sizes, not only for the case of their contact but also for the case of their overlapping. The method of obtaining this information was the same as in the cases described, e.g., in $[13,14]$.

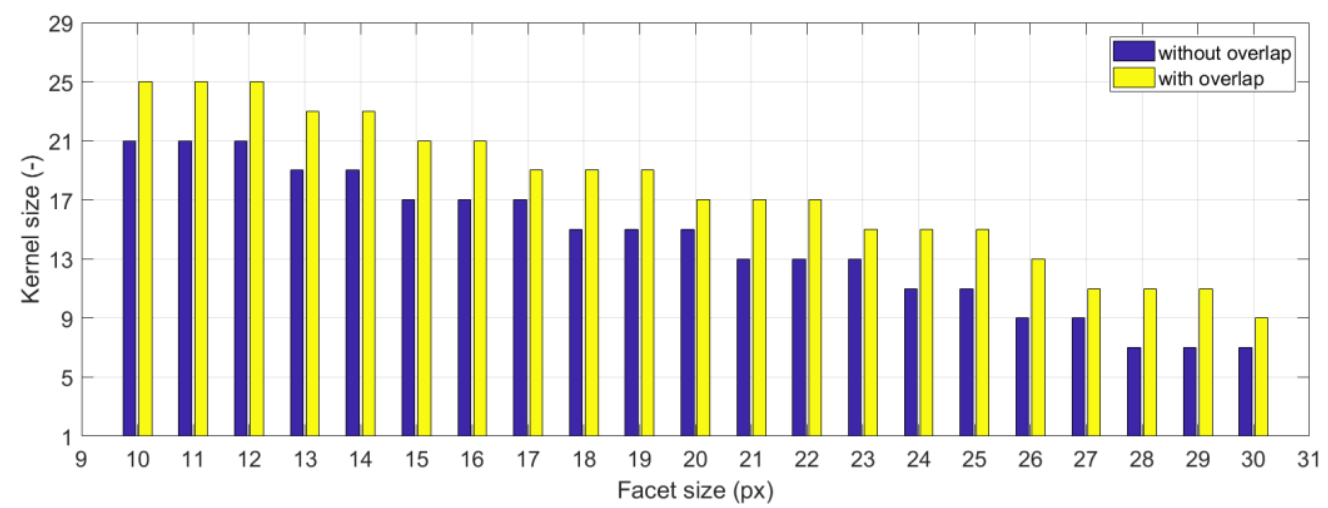

Fig. 6 Optimal smoothing levels (local regression) obtained for 2D DIC system Q-400 Dantec Dynamics

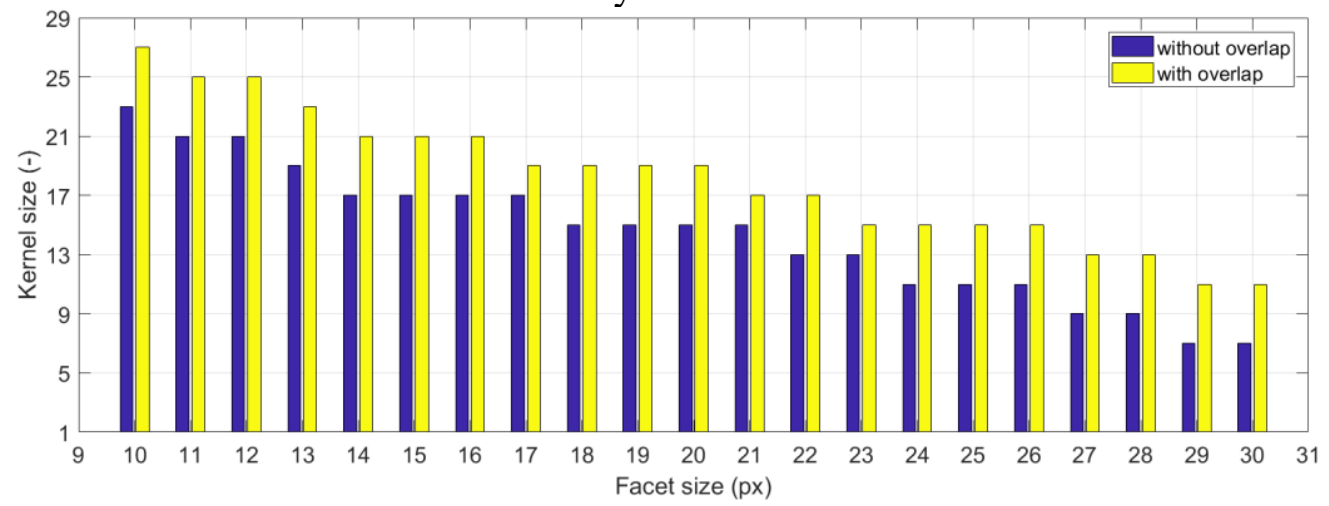

Fig. 7 Optimal smoothing levels (local regression) obtained for 3D DIC system Q-400 Dantec Dynamics 


\section{Possibilities of residual stress analysis using commercially available drilling and correlation systems}

In the process of quantifying residual stresses using the semi-destructive hole-drilling method, a through- or blind-hole is drilled into the structure to be analysed. The choice of one of these methods depends on the thickness of the specimen. A through-hole is milled by investigating a so-called thin specimen, where even distribution of residual stresses is assumed over its thickness. Suppose the measuring conditions permit, in the case of analysis of the relieved strains in the vicinity of the formed hole on a specimen of planar character using a DIC system. In that case, it is not necessary to change the relative position of the drilling and measuring device since the correlation system can be located on the opposite side of the specimen from the drilling device. For analysis carried out on thick specimen, where the uneven distribution of residual stresses is expected over the thickness, a blind-hole is created by successive (incremental) material removal from the specimen. The process of determining the residual stresses using the DIC system is therefore not as trivial as in the case of drilling a through-hole. It is due to the design of commercial drilling devices, the body of which covers a substantial part of the specimen. Therefore, the simultaneous use of drilling and correlation system is not possible, or even if it is, the measurement is made from a considerable distance, which reduces the data resolution. A simple approach to use commercially available drilling devices in combination with DIC systems and avoid these complications is to use the following procedure:

1) fix the feet of the drilling device on the specimen,

2) place the tripod with the correlation system as close as possible to the specimen and capture the reference state of the specimen (before drilling the hole),

3 ) turn the correlation system tripod on its side to gain space for the application of the drilling device,

4) attach the drilling device, mill to a depth of $k \cdot 0.1 \mathrm{~mm}$, where $k$ is the drilling step number, and remove the drilling device from the feet,

5) use the "virtual bearing" tool in ISTRA4D (see Fig. 8), try to return the tripod with the camera(s) to its reference position and capture the state of the specimen after deformation,

6) repeat steps 2 to 5 twenty times until the depth of the drilled hole reaches the desired level of $2 \mathrm{~mm}$.

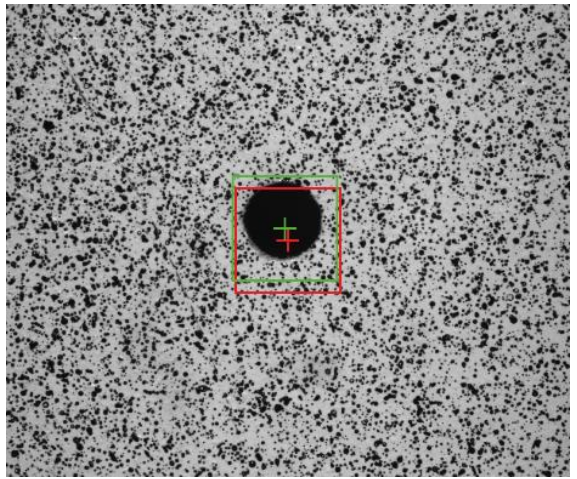

Fig. 8 Virtual bearing tool - reference position (red), actual position (green)

It should be noted that although the above-mentioned procedure does not conflict with any of the principles used in both methods, step 5 is so risky that using this procedure in practice can lead to serious errors. The authors have already analysed the effect of the inaccurate return of the correlation system to its reference position and described in [12]. By sensitivity analysis, i.e. by investigating the influence of the incomplete return of the correlation system to its reference position (its deviation from the reference plane) on the deviations in the 
principal strains evaluated on the area in the vicinity of the created hole, it was found that even a tiny deviation of the camera system will cause a significant relative difference, especially in the case of the use of a 2D DIC system. Based on the plots shown in Fig. 9, it can be concluded that there is an almost direct proportionality between the shift of the $2 \mathrm{D}$ DIC system from the reference plane and the relative deviation evaluated in the principal strains $\varepsilon_{1}$ and $\varepsilon_{2}$. Furthermore, even the most minor rotation of the camera causes a difference of approximately $15-19 \%$ [12].
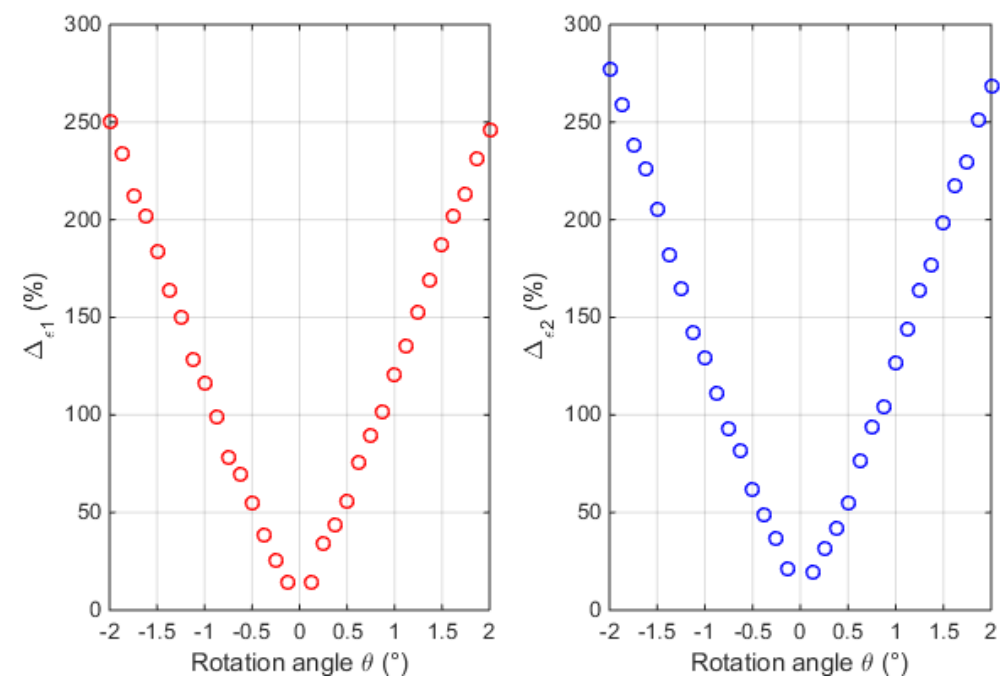

Fig. 9 Dependence of the mean relative deviation of the principle strains on the angle of rotation of the 2D DIC system with respect to the reference position of the camera [12]

The same procedure was applied when using a stereo-camera (3D DIC) system. Using a 3D DIC system introduces a radial or tangential distortion of the image or creates a shadow (covering) of a certain part of the specimen that cannot be evaluated. It also prolongs the calculation, because compared to 2D DIC there is a correlation of pairs of images instead of one. However, its use also introduces advantages such as the analysis of all three displacement components, not only for flat specimens but also for specimens with a curved contour. In this case, the analysed mean relative deviations of the evaluated principal strains reached approximately constant values within the rotation of the image planes of the cameras in the range from $0^{\circ}$ to $2^{\circ}$. The deviations in $\varepsilon_{1}$ reached the values of approximately $4-5 \%$, the deviations in $\varepsilon_{2}$ were much higher, i.e. approximately $12-14 \%$ (see Fig. 10) [12]. The authors attribute the higher difference in $\varepsilon_{2}$ to the lower sensitivity of the correlation systems when analysing lower strain levels.

The above-mentioned mean relative deviations result from the correlation errors arising from the change of the position of the image plane of the camera(s) and causing changes in the distribution of the analysed variables over the whole evaluated area [12]. The obtained results confirm that the above-described simple procedure without improving the positioning accuracy of the correlation system when it changes its reference position leads to systematic errors and obtaining results without being affected by a serious measurement error would be extremely difficult, especially in the case of using a 2D DIC system. In addition, the tripod with the correlation system cannot always be placed in a suitable position so that the distance of the analysed specimen from the image plane of the cameras is as small as possible. 

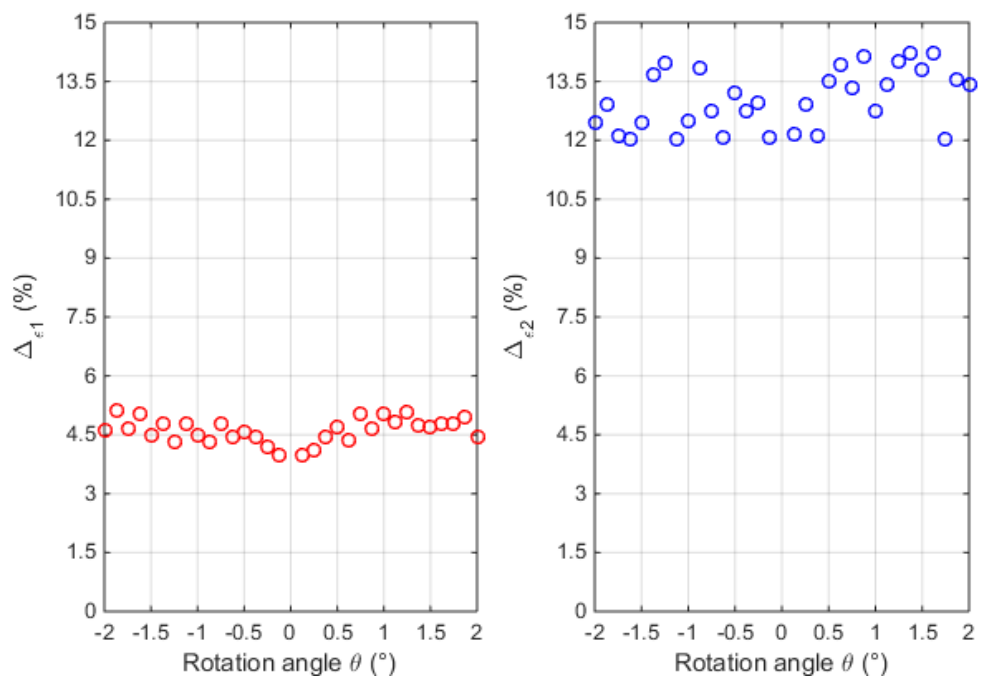

Fig. 10 Dependence of the mean relative difference of the principle strains on the angle of rotation of the 3D DIC system with respect to the reference position of the cameras [12]

\section{Possibilities of residual stress analysis using custom drilling/measuring device using a 2D or 3D DIC system}

Since in the process of measuring residual stresses by the hole-drilling method, it is necessary in most cases to create a blind-hole by successive removal of material, the accuracy of the results obtained by the correlation system is influenced by the accuracy with which the correlation system returns to its reference position. As mentioned above, even a minimal rotation of the camera system can cause a significant correlation error, especially when using a 2D DIC system. However, in the case of tiny displacement deviations (level on the order of several $\mu \mathrm{m}$ ), it can be assumed that the effect of correlation errors will not be severe enough to significantly affect the values of the evaluated relieved strains/stresses. For this reason, the authors designed and constructed a custom drilling/measuring device to enable an automatic blind-hole drilling process with a sequential recording of the fields of relieved strains or stresses of points in the hole's vicinity using Q-400 Dantec Dynamics correlation system (Fig. 11).

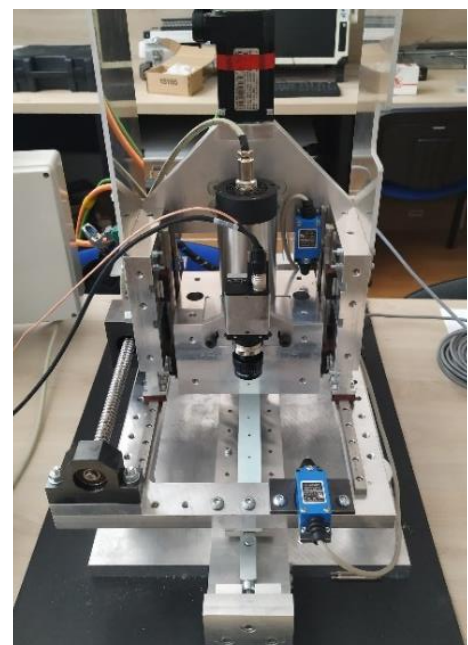

a)

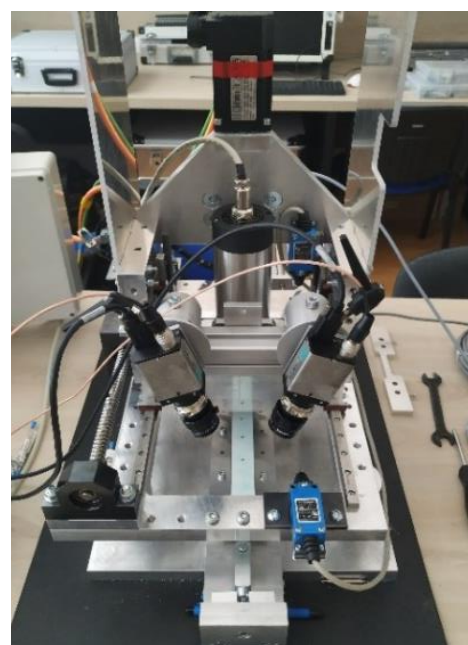

b)

Fig. 11 Custom drilling/measuring device for quantification of residual stresses using: a) 2D

DIC, b) 3D DIC 


\subsection{Analysis of the influence of the mutual change of the position of the drilling and correlation system on the results of the strain/stress analysis carried out in the vicinity of the hole}

Full-field analysis of deformations and stresses was performed on a specimen made of Vishay PS-1D material with a thickness of $\mathrm{t}=0.5 \mathrm{~mm}$, which is used in the PhotoStress method. The mechanical properties of the analysed material are Young's modulus of elasticity $\mathrm{E}=2500 \mathrm{MPa}$, Poisson's ratio $\mu=0.38$. The specimen, whose shape and dimensions are shown in Fig. 12a, was subjected to uniaxial tensile loading, while the magnitude of the tensile force was recorded by the HBM RSCC-50kg sensor and displayed on the display of the Vishay P3 strain indicator (Fig. 12b).

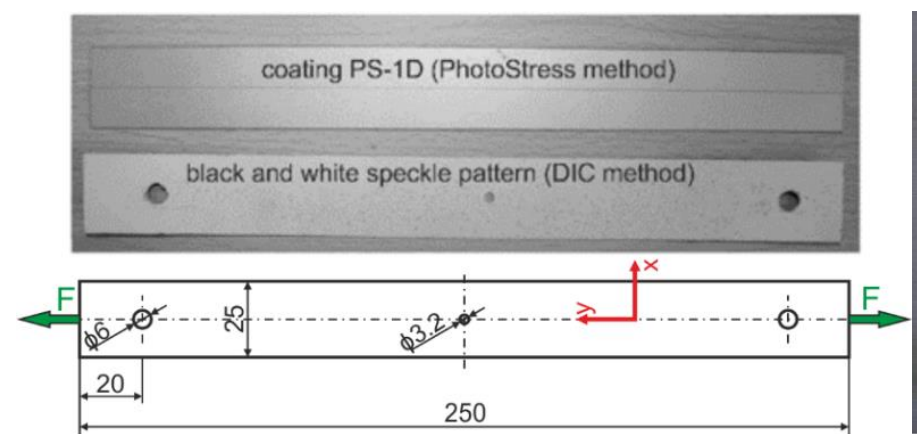

a)

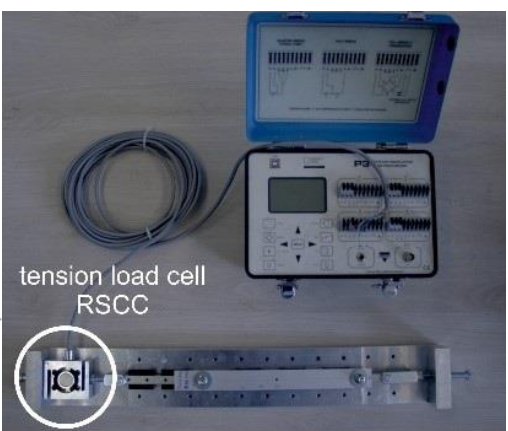

b)

Fig. 12 a) The dimensions and shape of the analysed specimen, b) the measuring string recording the magnitude of the tensile force

The main factors influencing the results of experimental measurements carried out by digital image correlation systems include:

- obtaining images with the highest possible quality (image resolution, uniform and sufficient illumination, etc.),

- the accuracy of the calibration of the camera system,

- the correct adjustment of correlation parameters such as facet size or smoothing levels.

Since the results of the analyses performed by the DIC system also depend on the quality of the acquired images (which need to be acquired with the highest possible image resolution), the correlation system was attached to the designed drilling device in positions allowing the record of the surroundings of the milled hole on the specimen, as shown in Fig. 13 for the 2D DIC system and Fig. 14 for the 3D DIC system, respectively. Since, according to the manufacturers of the Dantec Dynamics equipment, the largest correlation error occurs at the edge of the analysed objects, the area to be evaluated was reduced to an area of approximately $19 \times 19 \mathrm{~mm}^{2}$ shown in yellow in the two above-mentioned figures, which should be large enough to have sufficient measured data to calculate the residual stresses. The images, recorded with an image resolution of $2452 \times 2056 \mathrm{px}$ (pixel density of approximately 88 px/mm) and shown in Fig. 13 and Fig. 14, are reference images of the analysed specimen (i.e. obtained before the stress state was induced).

The analysed specimen was loaded in 10 steps (1 step corresponded to a force increase of $12 \mathrm{~N}$ ) with a uniaxial tensile force, which gradually increased from a value of $0 \mathrm{~N}$ to a final value of $\mathrm{F}_{\max }=120 \mathrm{~N}$. This procedure induced a stress state in the specimen material characterising the simulated (residual) stress. In Fig. 15, one can see the fields of reduced von Mises stresses and the fields of the individual displacement components obtained by MOSTRAN v.1.0 [15] for a chosen facet size of $28 \times 28 \mathrm{px}$ with their overlap of $7 \mathrm{px}$ and the 
corresponding smoothing level according to Fig. 6 and Fig. 7, respectively. While the 2D DIC system recorded and evaluated only the displacement components in the plane parallel to the camera image plane, all three displacement components were obtained in the case of the 3D DIC system.

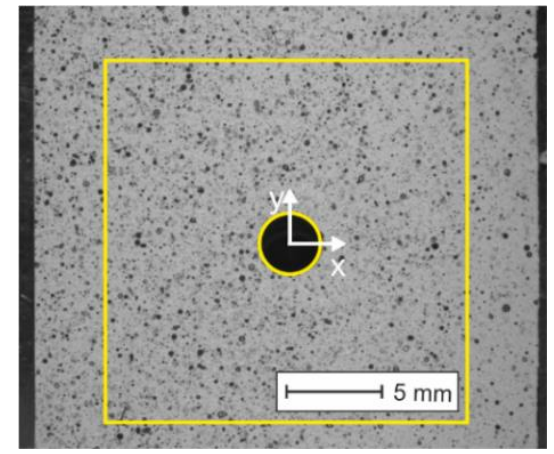

Fig. 13 Reference image recorded by the 2D DIC system Q-400 Dantec Dynamics with the marked area to be evaluated

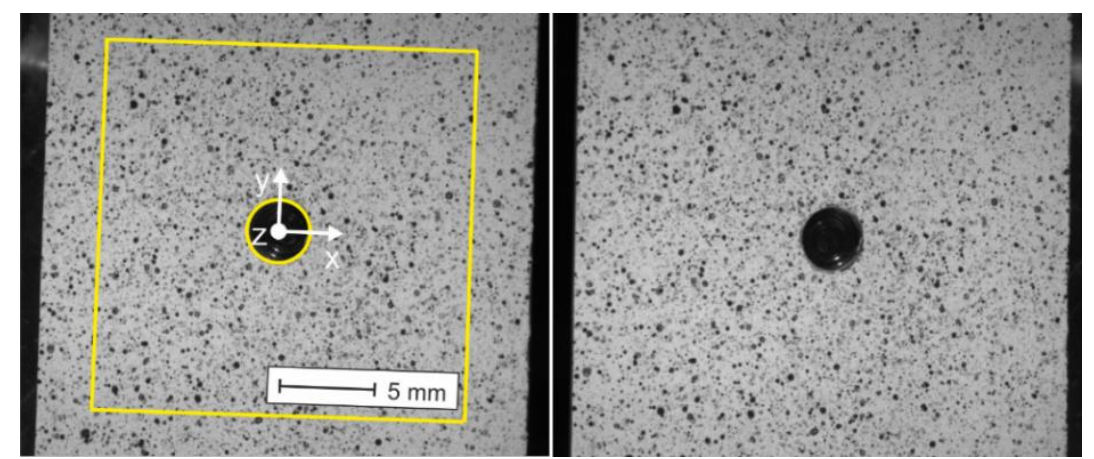

Fig. 14 Reference images recorded by the 3D DIC system Q-400 Dantec Dynamics with the marked area to be evaluated

In the next phase of the measurement, a procedure was carried out to mimic that used for quantifying residual stresses in thick specimens, i.e. making a blind hole and recording the strains released by sequentially removing material in 20 steps until a drilled hole depth of $2 \mathrm{~mm}$ was reached. This approach thus leads to 20 mutual position changes between the drilling and correlation system (Fig. 16).

In the paper [9], the authors describe how the displacement or strain fields, relieved after drilling a through-hole in a specimen of the same dimensions as in Fig. 12a, obtained experimentally and by finite element analysis, differ from each other. In the above-mentioned approach involving a single mutual change of the position between the drilling and correlation system, it was found that for the evaluation of residual stresses, a circular area of approximately $10 \mathrm{~mm}$ in diameter was the most suitable part of the specimen. In that case, the deviations between the measured and numerically obtained results reached levels of 13-20\%, which, according to [16], is the inaccuracy that should be considered when using DIC for residual stress analysis.

In the next phase of the analyses, it was necessary to investigate how multiple mutual changes in the position between the drilling and correlation system would affect the strainstress analyses performed on the specimen with drilled hole. Under ideal conditions, i.e. if the correlation system still returned precisely to its reference position (or did not move from it), the displacement and strain fields with a mean relative difference of approximately $1 \%$ and $3 \%$, respectively, should be obtained, which was demonstrated by recording 30 images of the analysed specimen captured and evaluated under the same measurement and loading conditions. The drilling/measuring system (milling cutter and camera system together) was 


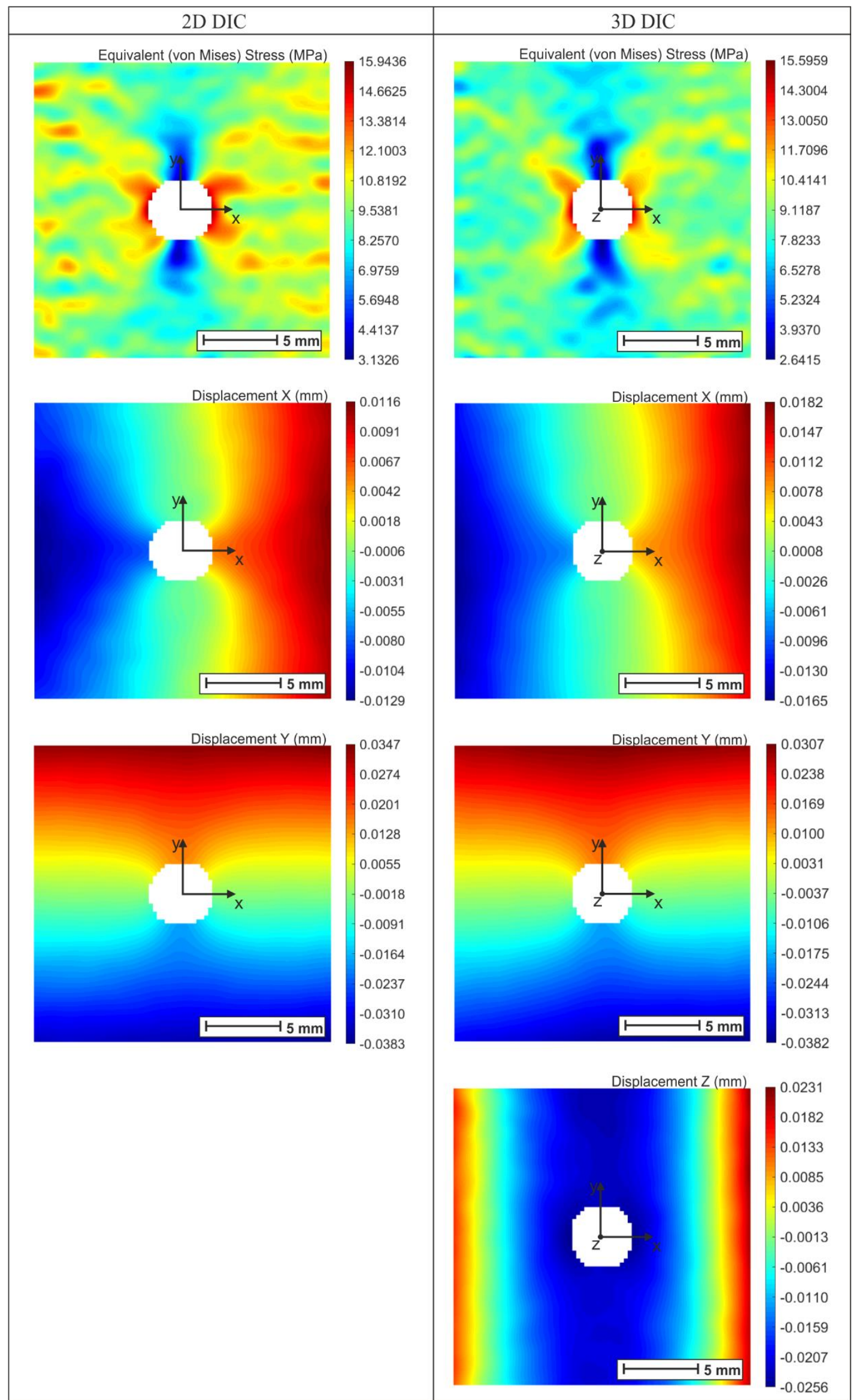

Fig. 15 Equivalent von Mises stress and displacement fields obtained after maximum loading the specimen by 2D DIC (1st column) and 3D DIC system (2nd column), respectively 


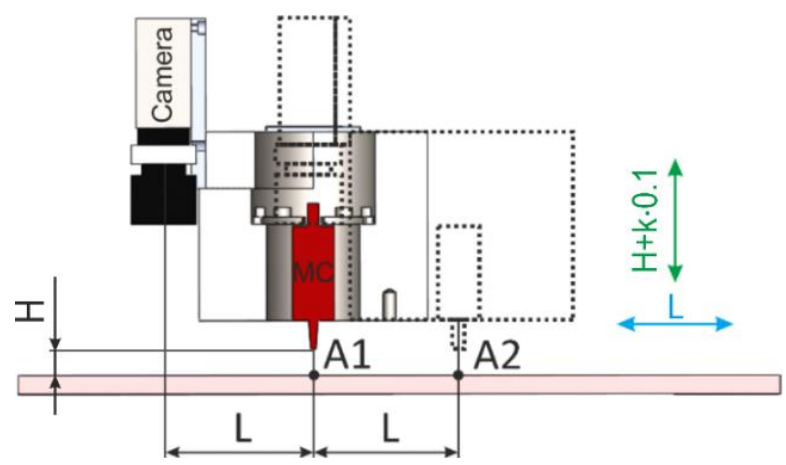

Fig. 16 Position between the drilling and measuring system and their necessary shifts in the horizontal and vertical direction

shifted in two directions - horizontally by a distance of $\mathrm{L}_{2 \mathrm{D}}=81 \mathrm{~mm}$ and $\mathrm{L}_{3 \mathrm{D}}=150 \mathrm{~mm}$ (forward and backward, respectively), which characterise the distances between the axis of the milling cutter and the focal point of the camera lens $\left(\mathrm{L}_{2 \mathrm{D}}\right)$ and the focal point of the camera lens $\left(\mathrm{L}_{3 \mathrm{D}}\right)$, respectively. In the vertical direction (down and up) by the distance $\mathrm{H}+k \cdot 0.1 \mathrm{~mm}$, where $\mathrm{H}=10 \mathrm{~mm}$ is the distance of the milling cutter from the specimen surface, $k$ is the step number and $0.1 \mathrm{~mm}$ is the increment of the material removal in each measurement step (Fig. 16). After each return of the camera system to the starting position, image(s) of the analysed specimen was/were captured by the correlation system.

Since the measurement was carried out under the same conditions as the measurement of the specimen deformation, the correlation system itself provided information on the accuracy with which the camera system returned to its original position by comparing the coordinates of the evaluated surface points of the specimen. This process had already been verified in the initial testing of the drilling/measuring system when the results obtained by the correlation system were compared with the deviations recorded by the inductive displacement transducer [9]. While the 2D DIC system records the positions of the points only in the plane parallel to the camera image plane (in the directions denoted as $\mathrm{x}$ and $\mathrm{y}$ ), when using the 3D DIC system, all three spatial components of the displacements can be obtained. Fig. 17 and Fig. 18 show the mean coordinate deviations of the specimen surface points obtained by the 2D DIC and 3D DIC system, respectively and calculated according to

$$
\begin{aligned}
& \Delta X_{k}^{\text {mean }}=\operatorname{mean}\left(X_{k}(a, b)-X_{\text {ref. }}(a, b)\right), \\
& \Delta Y_{k}^{\text {mean }}=\operatorname{mean}\left(Y_{k}(a, b)-Y_{\text {ref. }}(a, b)\right), \\
& \Delta Z_{k}^{\text {mean }}=\operatorname{mean}\left(Z_{k}(a, b)-Z_{\text {ref. }}(a, b)\right),
\end{aligned}
$$

where variables $X, Y$ and $Z$, respectively, represent the 3D coordinates of the specimen surface points with image coordinates $(a, b)$, subscript $k$ represents the step number and ref. denotes the reference state of the specimen obtained by its maximum load.

Based on the above, it can be concluded that the camera system returned to its original position with a determined maximum deviation of approximately $10 \mu \mathrm{m}$, which was recorded in the direction of the largest displacement, which corresponds approximately to the accuracy of the positioning device achieved so far.

The captured twenty images/pair of images were correlated using the same correlation parameters (facet size, overlapping and smoothing level) as above. The obtained fields of displacement components and equivalent von Mises stress, respectively, were compared with the results obtained at the maximum load of the specimen. It should be noted that rigid motions were filtered out from the fields of the individual displacement components, and thus 
the compared fields should not be affected by the motion of the camera system but should only correspond to the deformation of the specimen itself. The relative deviations of the displacement components obtained in the analysis performed by the 2D DIC and 3D DIC systems as the mean values of the whole evaluated specimen area according to

$$
\begin{aligned}
& \Delta \operatorname{dispX_{k}^{\text {mean}}}=\operatorname{mean}\left(\operatorname{abs}\left(\frac{\operatorname{disp} X_{k}(a, b)-\operatorname{disp} X_{\text {ref. }}(a, b)}{\operatorname{disp} X_{\text {ref. }}(a, b)}\right) \cdot 100 \%\right), \\
& \Delta \operatorname{dispY_{k}^{\text {mean}}}=\operatorname{mean}\left(\operatorname{abs}\left(\frac{\operatorname{disp} Y_{k}(a, b)-\operatorname{disp} Y_{\text {ref. }}(a, b)}{\operatorname{disp} Y_{\text {ref. }}(a, b)}\right) \cdot 100 \%\right), \\
& \Delta \operatorname{disp} Z_{k}^{\text {mean }}=\operatorname{mean}\left(\operatorname{abs}\left(\frac{\operatorname{disp} Z_{k}(a, b)-\operatorname{disp} Z_{\text {ref. }}(a, b)}{\operatorname{disp} Z_{\text {ref. }}(a, b)}\right) \cdot 100 \%\right),
\end{aligned}
$$

where variables dispX, dispY and dispZ, respectively, correspond to the displacements evaluated at specimen surface points with image coordinates $(a, b)$ after filtering out the rigid motion of the specimen, subscript $k$ represents the step number and ref. denotes the reference state of the specimen obtained by its maximum load, are shown in Fig. 19 and Fig. 20.

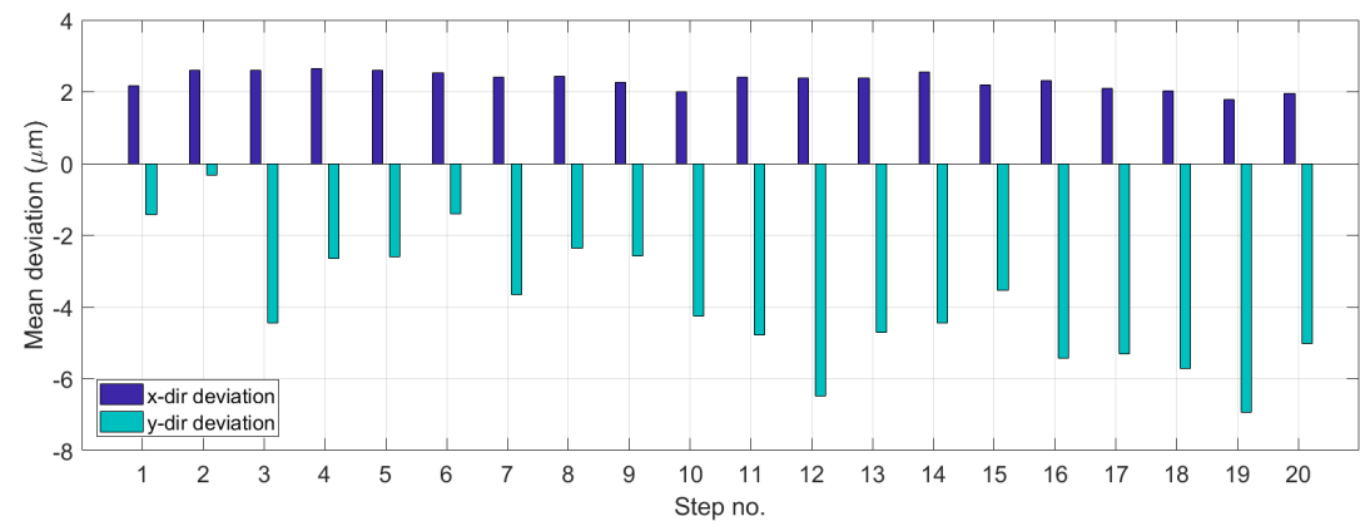

Fig. 17 The mean deviations from the reference position of the 2D DIC system recorded at each measurement step after making the mutual change of position between the drilling and measuring system

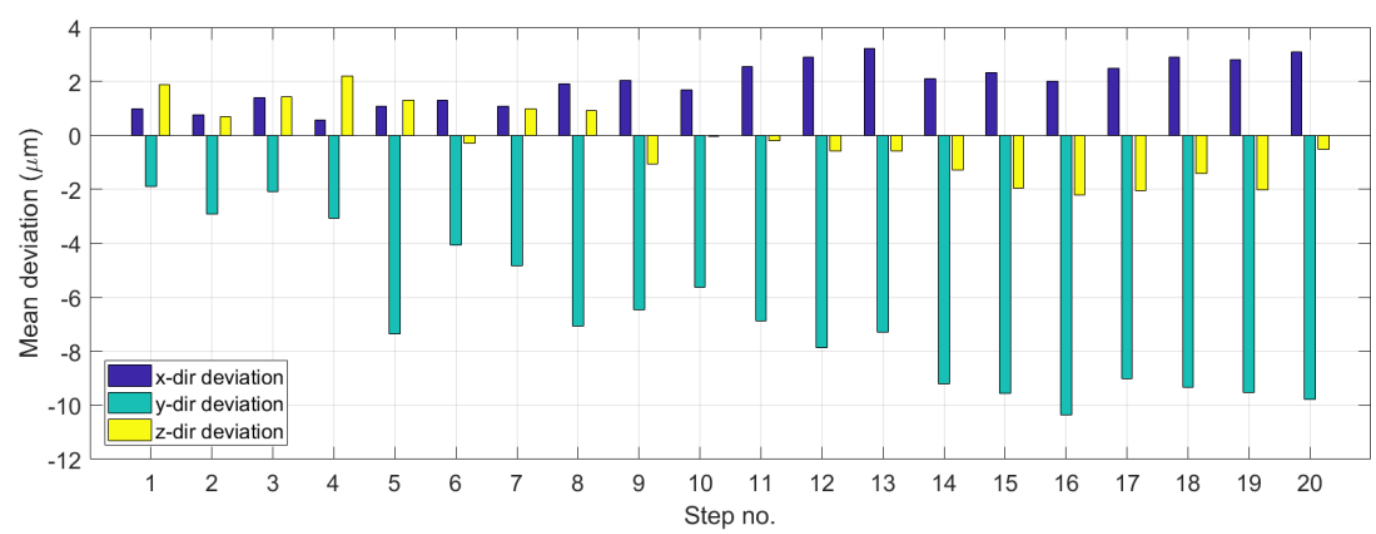

Fig. 18 The mean deviations from the reference position of the 3D DIC system recorded at each measurement step after making the mutual change of position between the drilling and measuring system 


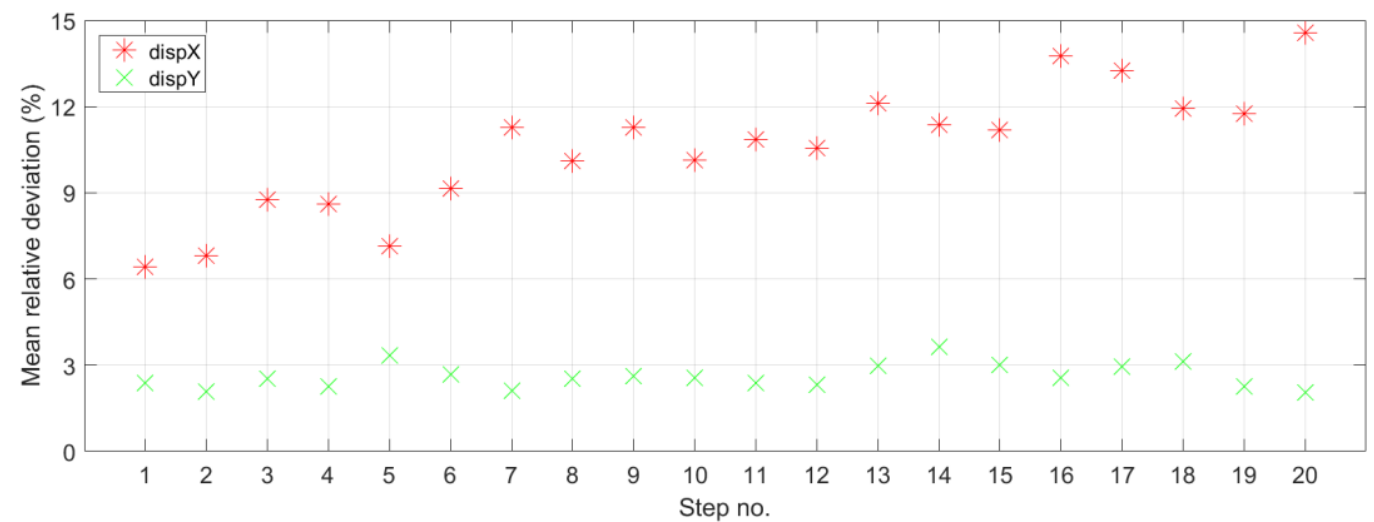

Fig. 19 Mean relative deviations of the displacement components evaluated at each measurement step by the mutual change of position between the drilling and 2D DIC system

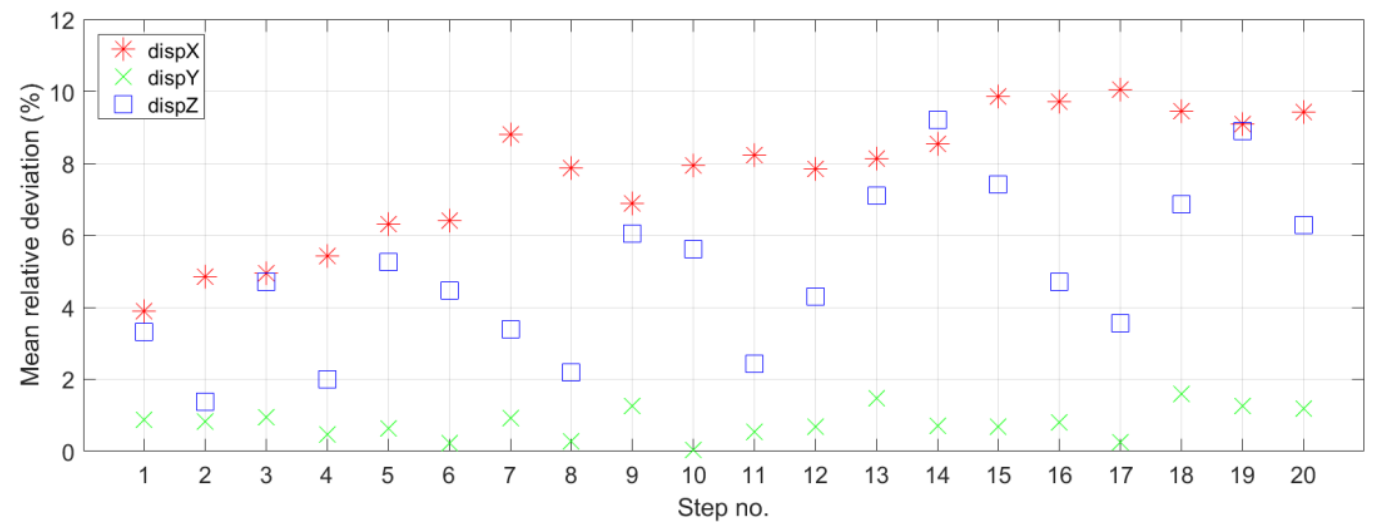

Fig. 20 Mean relative deviations of the displacement components evaluated at each measurement step by the mutual change of position between the drilling and 3D DIC system

While the maximum deviations in the measured displacement components reach higher levels for displacement fields in the x-axis direction (approximately 15\% for 2D DIC and $10 \%$ for 3D DIC, respectively) and z-axis direction (approximately $9 \%$ for 3D DIC), the deviation is smallest for displacements recorded in the loading direction of the specimen, i.e., in the y-direction.

The mean deviations in the equivalent von Mises stress fields (Fig. 21 and Fig. 22) were obtained according to

$$
\Delta \sigma_{k}^{\text {Mises }}=\operatorname{mean}\left(\operatorname{abs}\left(\frac{\sigma_{k}^{\text {Mises }}(a, b)-\sigma_{\text {ref. }}^{\text {Mises }}(a, b)}{\sigma_{\text {ref. }}^{\text {Mises }}(a, b)}\right) \cdot 100 \%\right),
$$

where $\sigma^{\text {Mises }}$ is the equivalent von Mises stress obtained at specimen surface points with image coordinates $(a, b)$, subscript $k$ represents the step number and ref. denotes the reference state of the specimen obtained by its maximum load. The analysed deviation in the equivalent von Mises stress reached the levels between $4.5-7.3 \%$ for 2D DIC and $4.2-5.8 \%$ for 3D DIC system, respectively, which can be considered acceptable.

To find the optimal region around the hole, which should be further used to quantify the residual stresses through the developed drilling/measuring system, the obtained relative deviations were subjected to an analysis that documents how the variation of the investigated quantities occurs as a function of the distance from the center of the milled hole. The relative deviations of the compared quantities obtained in twenty measurement steps were averaged 
over 15 concentric areas $A_{i}$ with a width of 2 facets, i.e. approximately $0.5 \mathrm{~mm}$, according to the relation

$$
\Delta Q_{i}=\operatorname{mean}\left(\operatorname{abs}\left(\frac{Q_{k}\left(a_{i}, b_{i}\right)-Q_{\text {ref. }}\left(a_{i}, b_{i}\right)}{Q_{\text {ref. }}\left(a_{i}, b_{i}\right)}\right) \cdot 100 \%\right)
$$

where $i$ is the area number (varying from the center of the hole to the edge of the area being evaluated), $Q$ is the quantity being evaluated (i.e., the three displacement components or von Mises stress), subscript $k$ represents the step number, ref. indicates the reference state of the specimen obtained by its maximum load, $\left(a_{i}, b_{i}\right)$ are the coordinates of the specimen surface points located at the $i$-th surface.

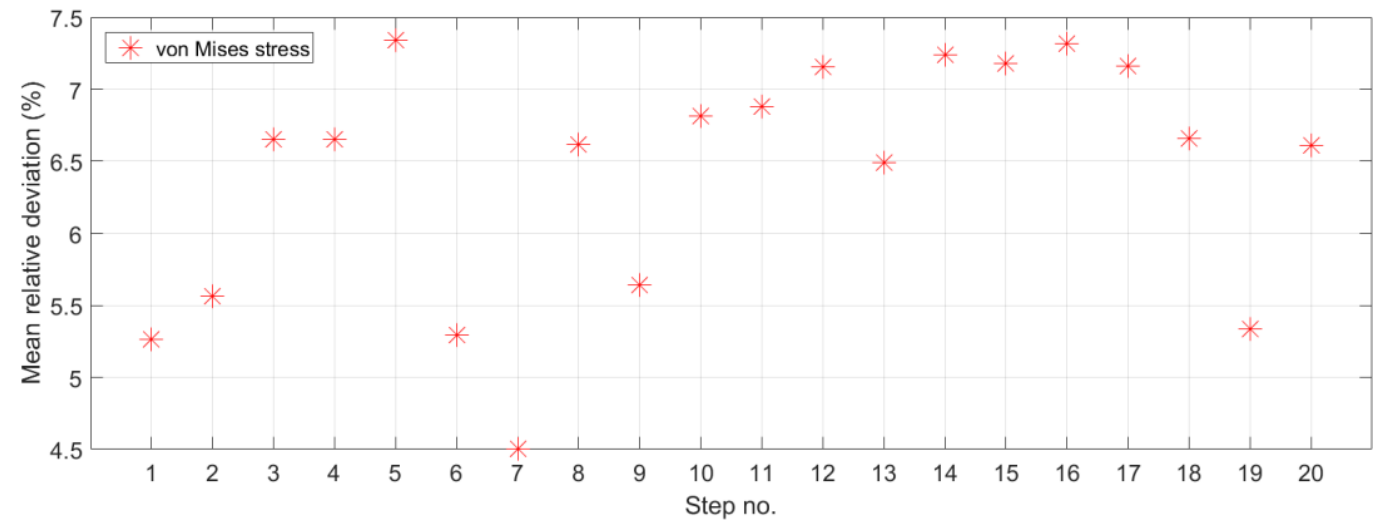

Fig. 21 Mean relative deviations of von Mises stress evaluated at each measurement step by the mutual change of position between the drilling and 2D DIC system

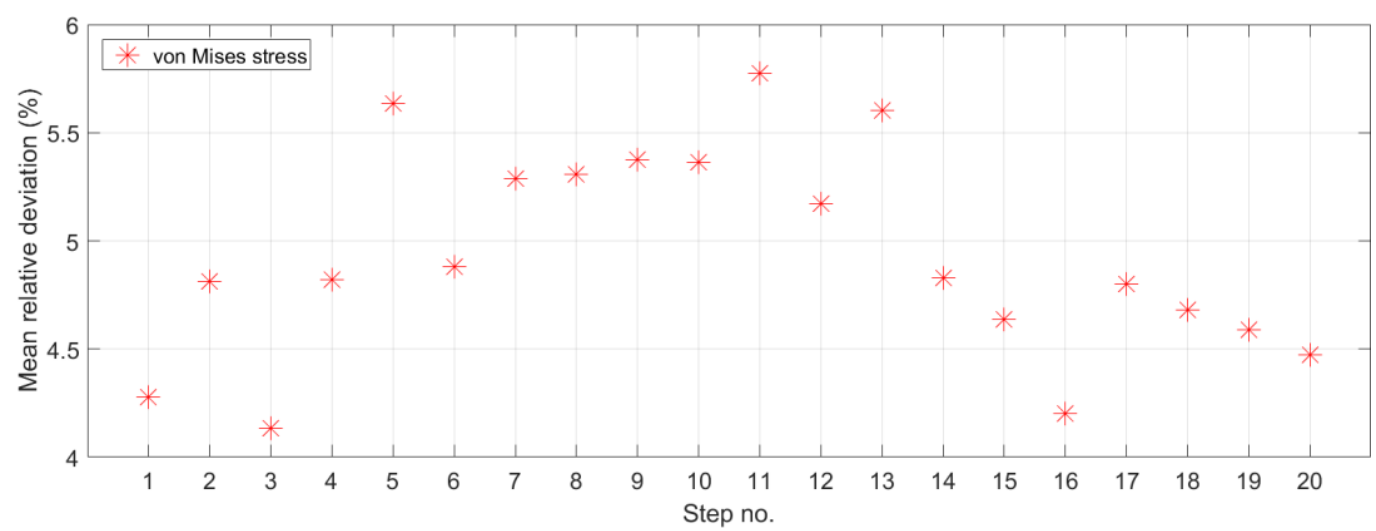

Fig. 22 Mean relative deviations of von Mises stress evaluated at each measurement step by the mutual change of position between the drilling and 3D DIC system

Based on the results obtained (Fig. 23), it can be concluded that the mean relative deviations recorded by the 3D DIC system show lower levels compared to the results obtained by $2 \mathrm{D}$ DIC. It should also be mentioned that the mean relative deviation obtained in the $\mathrm{x}-$ and z-displacements and von Mises stresses, respectively, increases with increasing distance from the centre of the hole in both approaches. It confirms the information found so far that the data used to quantify the residual stresses should be used from a close (but at the same time dimensionally sufficient) area surrounding the milled hole. When analysing the deviations in the y-displacements, it is impossible to pronounce the same conclusion as for the other quantities mentioned above. In this case, however, the deviations are significantly lower over the whole analysed sample area and reach a maximum level of approximately $3.3 \%$ (for 2D DIC). 


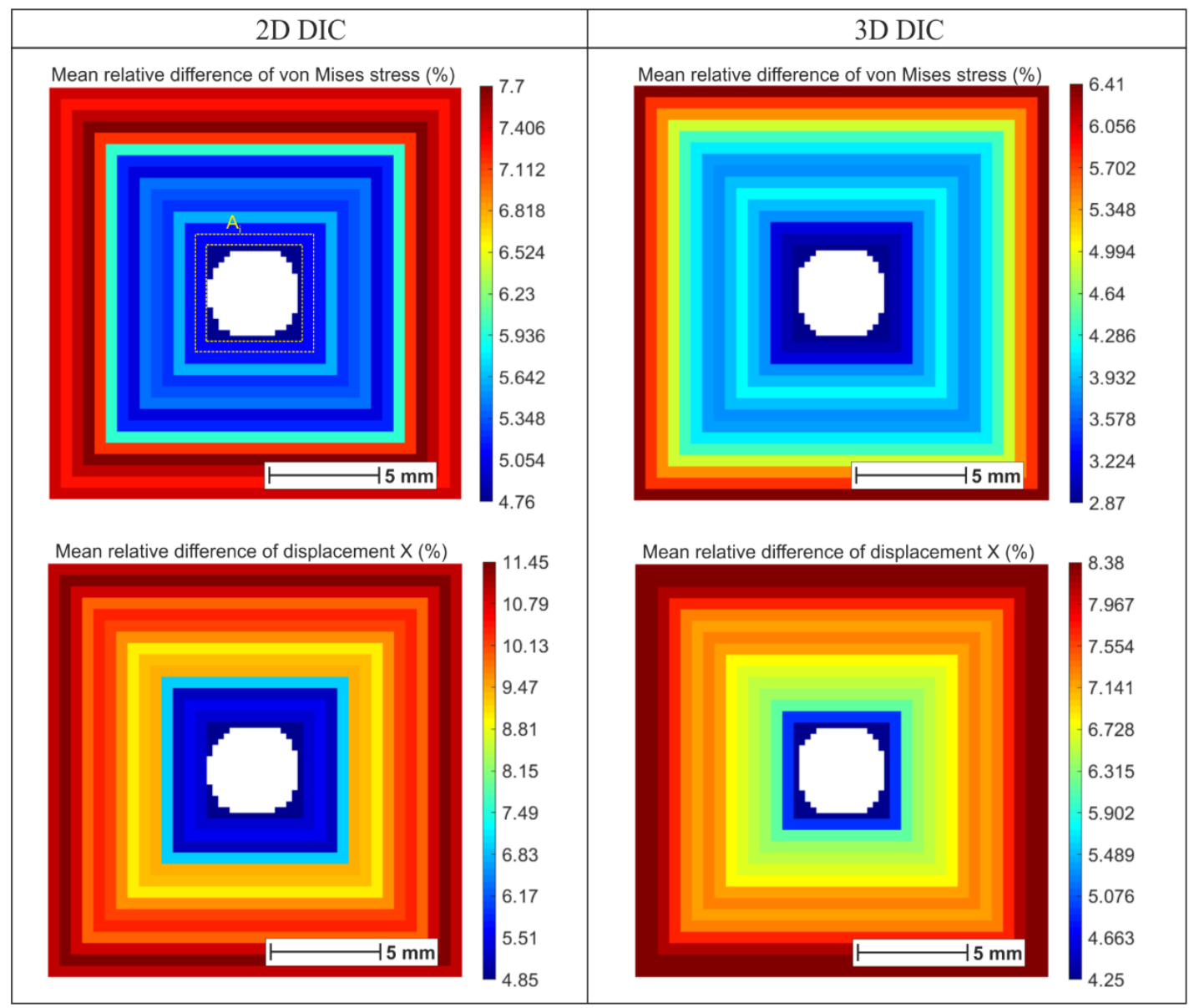

Fig. 23 Distribution of mean relative deviations as a function of distance from the centre of the hole

\section{CONCLUSION}

The papers published on the residual stress quantification using the digital image correlation method deals with a static (non-moving) correlation system. Such an approach is advantageous if the measurement conditions allow the correlation system to be located in the best possible position to the analysed structure. In this paper, essential aspects concerning the analysis of relieved deformations or stresses by means of a custom drilling device with a moving 2D or 3D DIC measurement system, respectively, are described.

Based on the analyses performed so far, it can be concluded that the use of the abovementioned drilling/measuring system is sufficiently accurate in terms of the accuracy of the blind- or through-hole formation and the positioning of the individual members. In particular, as pointed out, the mutual change of position between the milling cutter and the digital image correlation system can be a problem. If there is a deviation between the reference and the actual image plane of the correlation system camera(s), it will have a significant negative effect on the analysed deformation/stress fields.

However, the proposed device allows positioning the individual members with high accuracy (level of several $\mu \mathrm{m}$ ). For this reason, the authors have carried out an analysis to determine whether there is an accumulation of correlation measurement error in the process simulating the movement of the milling cutter during the creation of the blind-hole (by successive removal of material). Based on the results obtained, it can be concluded that a certain trend in the increase of the error in the analysis of the $\mathrm{x}$-axis displacement component can be observed. This trend is not present in the other deviations of the displacement 
components or the equivalent von Mises stress. The distribution of the mean relative deviation of the analysed quantities shows an increase in the measurement deviation with increasing distance from the hole. By analysing the results obtained in the authors' previously published papers, it can be concluded that to obtain the most accurate values of the deformations/stresses relieved, a circular/square part of the analysed area with a diameter/edge length of approximately $10-12 \mathrm{~mm}$ should be used. In this case, one can expect the results with an overall deviation of approximately $20 \%$, which can be considered acceptable towards the sensitivity of the digital image correlation systems.

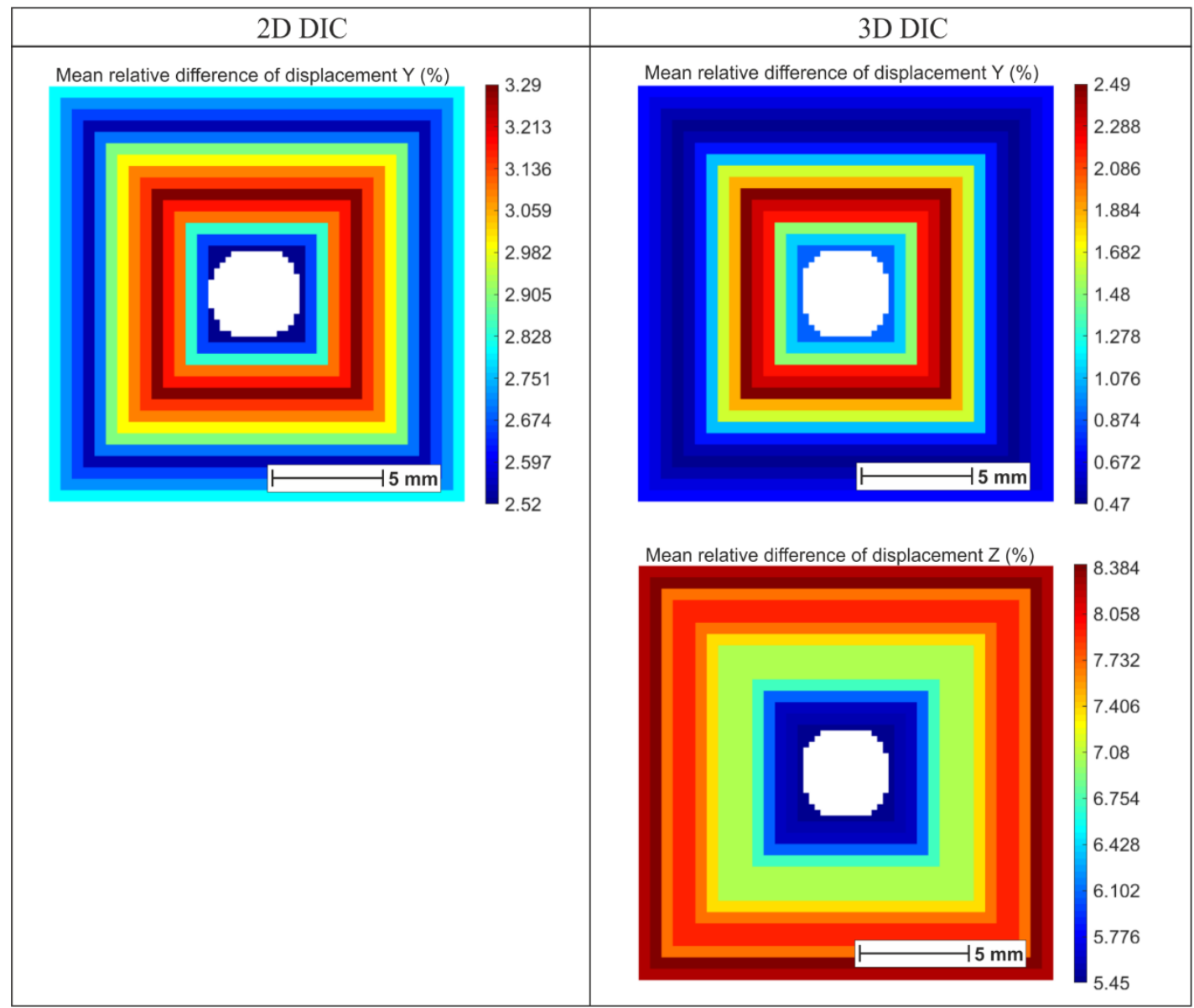

Fig. 23 (cont.) Distribution of mean relative deviations as a function of distance from the centre of the hole

\section{ACKNOWLEDGEMENT}

This research was funded by Slovak Grant Agency VEGA 1/0500/20 and APVV-15-0435.

\section{REFERENCES}

[1] Rendler, N.J., Vigness, I. "Hole-drilling strain-gage method of measuring residual stresses", Experimental Mechanics 6, pp. 577 - 586, 1966. DOI: 10.1007/BF02326825

[2] Pástor, M., Čarák, P., Gömöry, I.. "The Assessment of the Residual Stresses Influence on the Generation of the Infringement in Shape-Complex Supporting Members", Strojnícky časopis - Journal of Mechanical Engineering 69 (1), pp. 85 - 96, 2019. DOI: 10.2478/scjme-2019-0007 
[3] Menda, F., Trebuňa, F., Šarga, P. "New Method of Residual Stress Evaluation and its Advantages in Comparison with More Common Hole-drilling Method", Acta Mechanica Slovaca 17, pp. 64 - 70, 2013. DOI: 10.21496/ams.2013.048

[4] Aldajah, S. "Thermal residual stress development in a laser glazed carbon steel", Strojnícky časopis - Journal of Mechanical Engineering 60 (3), pp. 121 - 134, 2009.

[5] "ASTM E837-13a: Standard Test Method for Determining Residual Stresses by the Hole-Drilling Strain-Gage Method. ASMT international", West Conshohocken, PA, 2013.

[6] Viotti, M. R., Dolinko, A. E., Galizzi, G. E., Kaufmann, G. H. "A portable digital speckle pattern interferometry device to measure residual stresses using the hole drilling technique", Optics and Lasers in Engineering 44, pp. 1052 - 1066, 2006. DOI: 10.1016/j.optlaseng.2005.09.004

[7] Brynk, T., Romelczyk-Baishyaa, B. "Residual stress estimation based on 3D DIC displacement filed measurement around drilled holes", Procedia Structural Integrity 13, pp. 1267 - 1272, 2018. DOI: 10.1016/j.prostr.2018.12.259

[8] Pástor, M., Carák, P., Hagara, M. "Development of the Device with a High Positioning Accuracy Serving for Residual Stress Quantification using Optical Methods", Acta Mechanica Slovaca 23, pp. 24 - 29, 2019. DOI: 10.21496/ams.2020.005

[9] Pástor, M., Hagara, M., Virgala, I., Kal’avský, A., Sapietová, A., Hagarová L. "Design of a Unique Device for Residual Stresses Quantification by the Drilling Method Combining the PhotoStress and Digital Image Correlation", Materials 14, pp. $1-27$, 2021. DOI: $10.3390 / \mathrm{ma} 14020314$

[10] Siebert, T., Splitthof, K., Stecklum, S., Herbst, Ch. "New features in digital image correlation techniques", In: Proceedings of 22nd DANUBIA-ADRIA Symposium on Experimental Methods in Solid Mechanics, Parma: MONTICELLI TERME, 2005.

[11] Dantec Dynamics. "Q-400 User Manual", 2012.

[12] Hagara, M., Trebuňa, F., Pástor, M., Huňady, R., Lengvarský, P. "Analysis of the aspects of residual stresses quantification performed by 3D DIC combined with standardized hole-drilling method", Measurement 137, pp. 238 - 256, 2019. DOI: 10.1016/j.measurement.2019.01.028

[13] Hagara, M., Bocko, J. "The aspects of stress analysis performed by digital image correlation method related with smoothing and its influence on the results", Acta Mechatronica - International Scientific Journal about Mechatronics 3 (4), pp. 15 - 21, 2018. DOI: $10.22306 / a m . v 3 i 4.45$

[14] Hagara, M., Pástor, M., Delyová, I. "Set-up of the standard 2D-DIC system for quantification of residual stresses" In: Proceedings of EAN 2019 - 57th conference on experimental stress analysis, Luhačovice, Czech Republic, June 3-6, 2019.

[15] Hagara, M., Huňady, R., Lengvarský, P. "The post-processing possibilities of full-field stress/strain data obtained by the digital image correlation method", In: Proceedings of the 7th International Conference on Modelling of Mechanical and Mechatronic Systems, Sromowce Niżne, Poland, September 11 - 13, 2019.

[16] Schajer, G. S. "Practical Residual Stress Measurement Methods", 1st ed., A John Wiley \& Sons, Ltd., Chichester, United Kingdom, 2013. ISBN 978-1-118-34237-4, DOI: $10.1002 / 9781118402832$ 